\title{
Contractile and electrical activities of dexchlorpheniramine on rat hearts
}

\begin{abstract}
Dexchlorpheniramine is a first-generation H1-Antihistamine, and despite numerous studies on the cardiotoxicity of other first-generation H1-Antihistamines, the effects of dexchlorpheniramine on cardiac physiology are not well known. The objective of the present study was to characterize the action of dexchlorpheniramine on the amplitude of the force of contraction, and on the electrocardiographic parameters in isolated and perfused hearts of Wistar rats. The Langendorff isolated perfused heart technique was

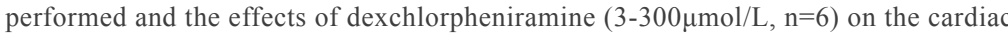
contraction and on the RR, QRS, QT and QTc parameters of the electrocardiogram were measured. The RR, QRS, and QT intervals increased by dexchlorpheniramine, not being so with the QTc interval. This probably suggests some type of action of dexchlorpheniramine on cardiac $\mathrm{K}+$ and $\mathrm{Na}+$ channels. The amplitude of the cardiac force of contraction decreased in concentration dependent manner, which suggests some effect on the $\mathrm{Ca} 2+$ current by dexchlorpheniramine. The IC50 estimated for the inhibition of the cardiac force of contraction was $4.12 \pm 1.64 \mu \mathrm{mol} / \mathrm{L}$.
\end{abstract}

Keywords: arrhythmia, cardiotoxicity, cardiovascular, dexchlorpheniramine, H1antihistamines, QT prolongation
Volume 7 Issue 5 - 2018

\section{Loipa Galán Martínez, Gabriel Emilio} Curbelo González

Departamento de Investigaciones, Instituto de Cardiología y Cirugía Cardiovascular, Cuba

Correspondence: Loipa Galán Martínez, Laboratorio de Electrofisiología, Departamento de Investigaciones, Instituto de Cardiología y Cirugía Cardiovascular, Paseo y 17, Vedado, CP 10400, La Habana, Cuba, Email lolpa@infomed.sld.cu

Received: July 31, 2017 | Published: October 15, 2018
Abbreviations: H1A, H1-antihistamines; hERG, human ethera-go-go-related gene

\section{Introduction}

H1-Antihistamines (H1A) act as inverse agonists that shift the balance towards the inactive state of the $\mathrm{H} 1$ histaminergic receptors. Since the 1970s reports began to appear of association between the consumption of H1A and the occurrence of cardiotoxicity reported in many revisions. ${ }^{2-6}$ Many studies have focused on elucidating which H1A and by which mechanisms they affect the functioning of the heart. Dexchlorpheniramine (D isomer of chlorpheniramine) is a first-generation $\mathrm{AH} 1$, is more potent than chlorpheniramine as antihistamic. ${ }^{7}$ Despite numerous studies on the cardiotoxicity of other first-generation $\mathrm{AH} 1$, the effects of dexchlorpheniramine on cardiac physiology are not well known. Chlorpheniramine (racemic mixture) blocks the delayed rectifier potassium channel $\mathrm{IKr}$, and it lengthens the action potential, slows cardiac repolarization, and prolongs the QTc interval. ${ }^{3,4,8-10}$

Salata et al. ${ }^{11}$ founded that $(+)$ chlorpheniramine also blocked $\mathrm{I}_{\mathrm{K} .}$ weakly, with $\mathrm{IC}_{50}$ values of $1.6 \mu \mathrm{mol} / \mathrm{L}$, and blocked $\mathrm{I}_{\mathrm{Ks}}$ slightly $(<20 \%)$ at high concentrations $(10 \mu \mathrm{mol} / \mathrm{L})$. In chloralose-anesthetized dogs, $(+)$ chlorpheniramine did not significantly alter the QTc interval and ventricular effective refractory period, in vivo indexes of ventricular repolarization at doses up to $3.0 \mathrm{mg} / \mathrm{kg} \mathrm{IV.}{ }^{11}$

In clinic, chlorpheniramine caused a lengthened in the QT segment or Torsades de pointes tachycardia in combination with others drugs such as thioridazine, ${ }^{12}$ common cold compound medication, ${ }^{13}$ lamotrigine and citalopram, ${ }^{14}$ and with propranolol. ${ }^{15}$ Therefore, the aim of the present study was to investigate the action of dexchorpheniramine on electrical and contractile activities of isolated rat hearts.

\section{Material and methods}

\section{Animals}

Male adult (7-8 weeks) Wistar rats were obtained from the National Center for Laboratory Animal Reproduction (CENPALAB; La Habana). Prior to the experiment, animals were adapted for seven days to laboratory conditions (controlled temperature $25 \pm 2^{\circ} \mathrm{C}$, relative humidity $60 \pm 10 \%$, and $12 \mathrm{~h}$ light/dark cycles). Tap water and standard diet for rodents supplied by CENPALAB were freely provided. All procedures were also conducted according to the European Commission guide-lines for the use and care of laboratory animals and approved by the Ethical Committee for Research of the Center (No. 02-2015, folio 3, book 01, 2015). The minimum number of animals $(n=6)$ required to obtain consistent data were employed.

\section{Isolated hearts}

As previously reported, ${ }^{16}$ under pentobarbital anesthesia rat hearts were removed and placed in cold Tyrode (see below). Rat hearts were carefully dissected, mounted on a Langendorff column and perfused at constant flow $(10 \mathrm{~mL} / \mathrm{min})$ with a Tyrode solution of the following composition (mmol/L): $140 \mathrm{NaCl}, 2.5 \mathrm{KCl}, \mathrm{MgCl} 2,2 \mathrm{CaCl}_{2}, 10$ Trishydroxymethylaminomethane, 10 Glucose $(\mathrm{pH}=7.4$, gassed with $\mathrm{O} 2 ; \mathrm{T}=35^{\circ} \mathrm{C}$ ). A bipolar platinum recording electrode was placed on the ventricular epicardium to record the surface electrocardiogram. Another bipolar platinum electrode was placed near the atrioventricular ring and was connected to an electronic stimulator.

The cardiac apex was fixed to a force-displacement transducer with a surgical 6-0 silk thread to record the force of contraction. Electrocardiogram and the force of contraction values were recorded at the spontaneous heart rate and at a fixed stimulus rate (200-ms RR interval). The incidence of arrhythmia was analyzed in accordance with the Lambeth Conventions (II). ${ }^{17}$ 


\section{Dexchlorpheniramine and chemicals}

A gift sample of dexchlorpheniramine maleate (molecular weight=390.86) raw material was supplied by BioCubaFarma, and it was diluted in the bathing solution on the day of the experiment. All other chemicals used in this experiment are of good quality from Sigma Aldrich.

\section{Statistical analysis}

Means and standard errors of means expressed the results. Student's t- test evaluated the statistical significance for paired samples, previously checked that the data complied with the premise of normality. Differences were considered statistically significant for $\mathrm{p}<0.05$. The graphics and the statistical processing were done using the software OriginPro 8 SRO v8.0724 (MA, USA).

\section{Results}

In the registered electrocardiogram, dexchlorpheniramine significantly prolonged the QRS (Figure 1A) and RR interval (Figure $1 \mathrm{~B})$ at the higher concentrations of the drug. In the QRS interval, the significant statistic $(p<0.05)$ differences were observed since $30 \mu \mathrm{mol} / \mathrm{L}$, while that in the RR interval, it occurred since $100 \mu \mathrm{mol} / \mathrm{L}$. The Figure $2 \&$ Figure 3 show experimental electrocardiogram registers of dexchorpheniramine and control condition with the prolongation of QRS and RR interval, respectively.

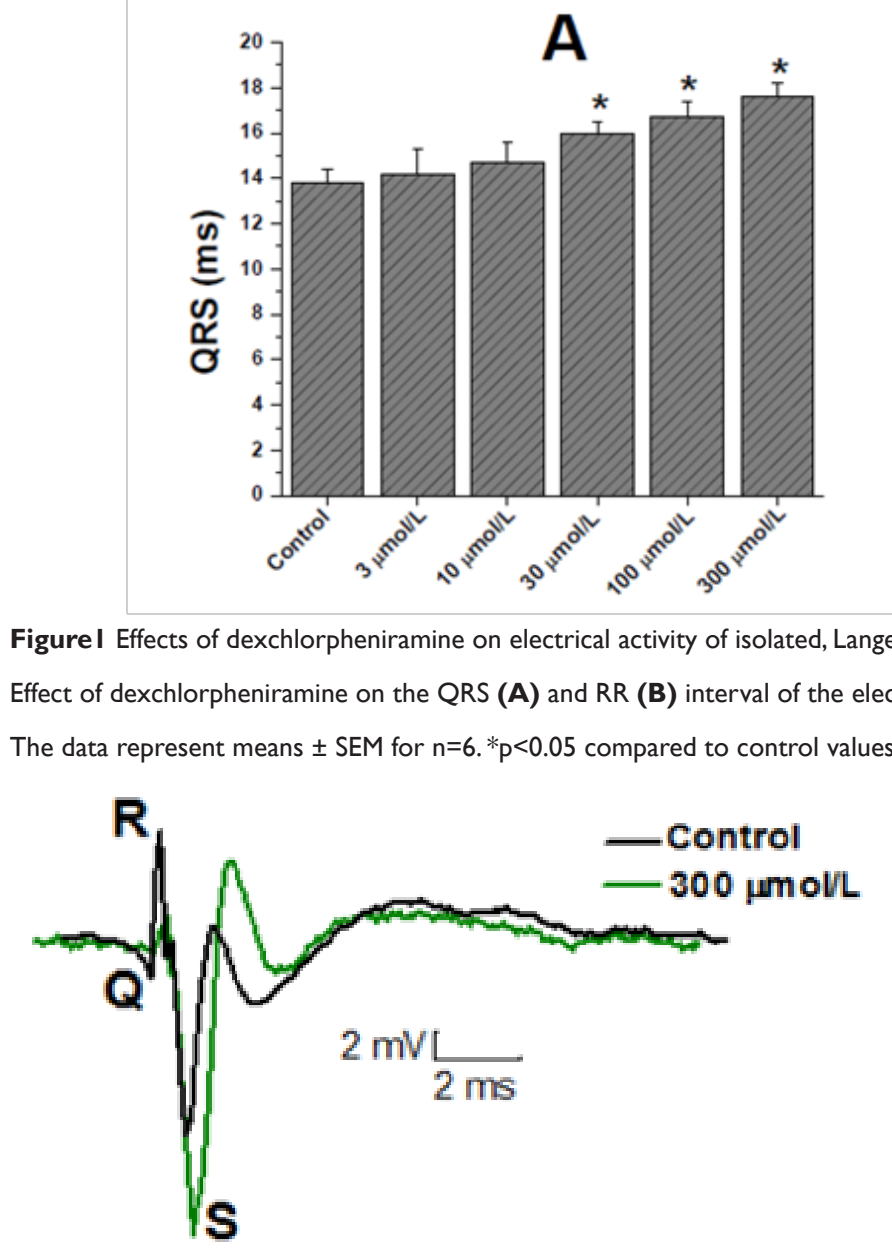

Figure 2 Effect of dexchlorpheniramine $300 \mu \mathrm{mol} / \mathrm{L}$ (green trace) on electrocardiographic patron in isolated, Langendorff-perfused rat heart. QRS complex was widened with respect to the control condition (black trace).

As QRS interval, the QT interval was slowed by dexchorpheniramine in significant manner since $30 \mu \mathrm{mol} / \mathrm{L}$ (Figure $4 \mathrm{~A}$ ). At the other hand this drug did not significantly alter the corrected $\mathrm{QT}(\mathrm{QTc}=\mathrm{QT} / \sqrt{\mathrm{RR}})$ interval (Figure 4B).

Dexchorpheniramine induced arrhythmias in all hearts studied. It showed a tendency to bradicardic effect with increasing concentration, since RR interval was significantly prolonged (Figure 3). Moreover, dexchlorpheniramine since $10 \mu \mathrm{mol} / \mathrm{L}$ induced ventricular premature beats (see an example in Figure 5), these were sustained or episodic in some cases.

The data represent means + SEM for $n=6 * p<0.0 \%$

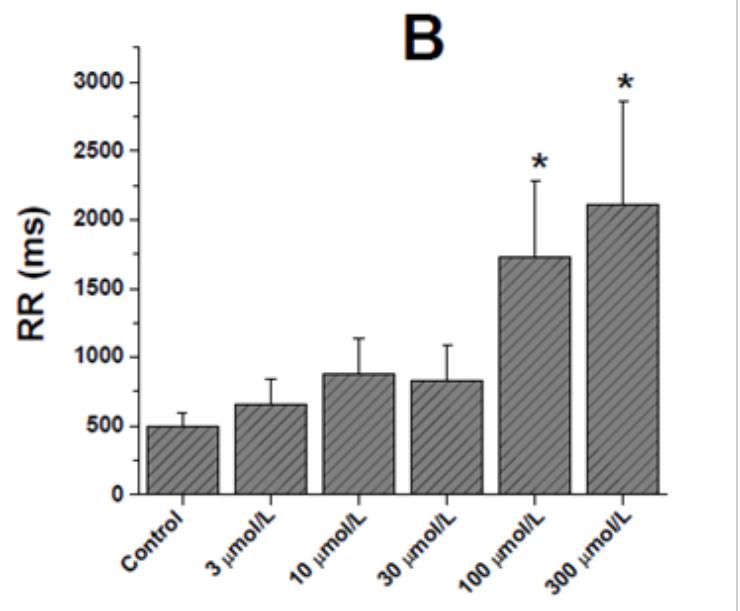

Figure I Effects of dexchlorpheniramine on electrical activity of isolated, Langendorff-perfused rat hearts.

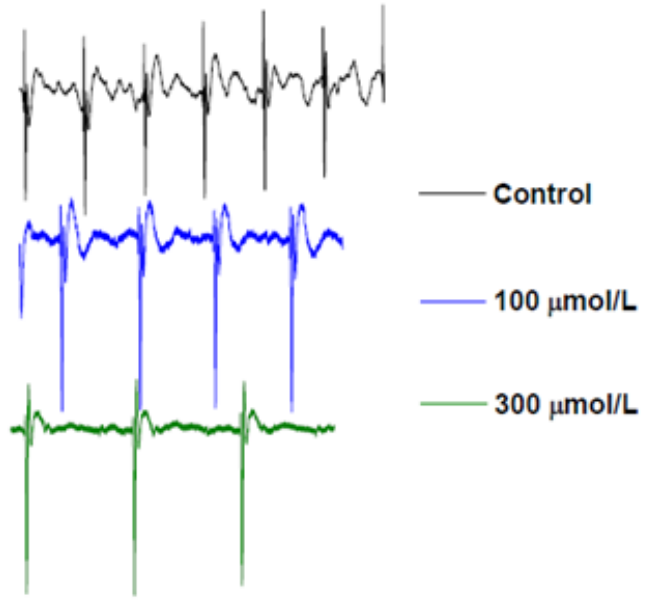

Figure 3 Effect of dexchlorpheniramine at different concentrations (100 and $300 \mu \mathrm{mol} / \mathrm{L}$ ) on electrocardiographic patterns in isolated, Langendorffperfused rat heart. RR interval was significantly prolonged.

Dexchorpheniramine showed a concentration-dependent decrease on the force of contraction of all hearts studied. At $10 \mu \mathrm{mol} / \mathrm{L}$ the inhibition of cardiac contraction was $52.24 \pm 11.55 \%$. At the higher concentrations 100 y $300 \mu \mathrm{mol} / \mathrm{L}$ of dexchorpheniramine the percentage inhibition were $63.4 \pm 23.53 \%$ y $75.65 \pm 19.87 \%$, respectively (Figure $6)$. The IC50 for this inhibition was $4.12 \pm 1.64 \mu \mathrm{mol} / \mathrm{L}$. 
A

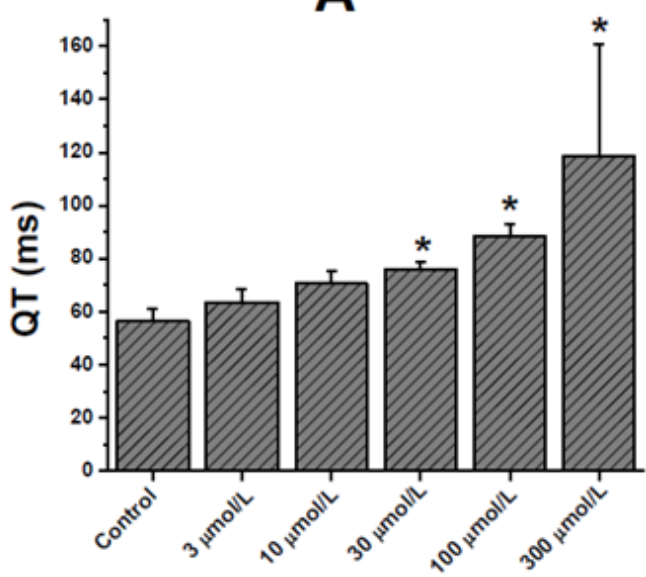

B

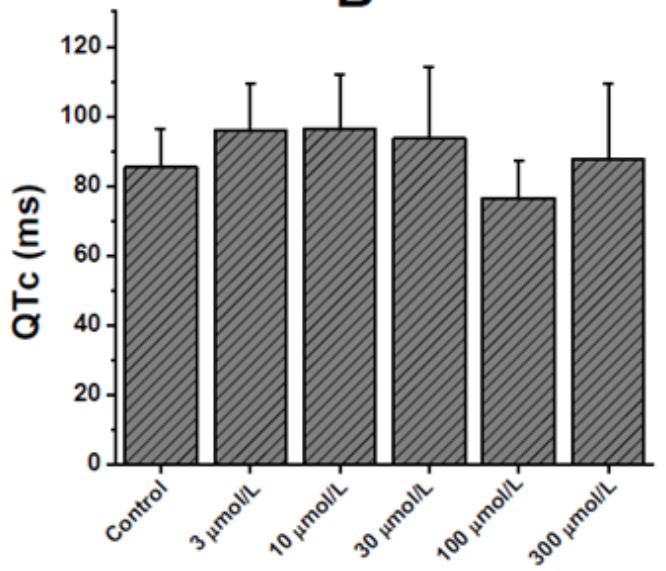

Figure 4 Effects of dexchlorpheniramine on electrical activity of isolated, Langendorff-perfused rat hearts.

Effect of dexchlorpheniramine on the QT (A) and QTc (B) interval of the electrocardiogram recorded in isolated rat hearts.

The data represent means \pm SEM for $n=6$. ${ }^{*} p<0.05$ compared to control values.

Control

- Dexchlorpheniramine $10 \mu \mathrm{mol} / \mathrm{L}$

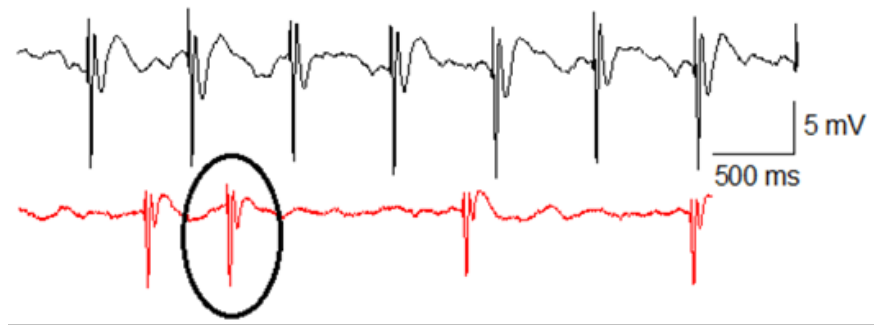

Figure 5 Example of arrhythmic effect of dexchlorpheniramine at $10 \mu \mathrm{mol} / \mathrm{L}$ in isolated, Langendorff-perfused rat heart on electrocardiogram. The circle indicates the induction of a ventricular premature beat by $10 \mu \mathrm{mol} / \mathrm{L}$ of dexchlorpheniramine. Note also the bradicardic effect.

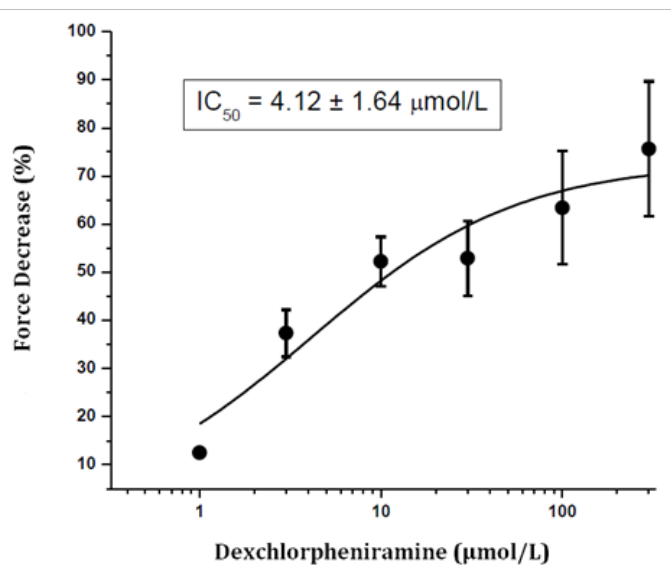

Figure 6 Effect of dexchlorpheniramine on contractile activity of isolated, Langendorff-perfused rat hearts. Experimental data $(n=6)$ were fitted to a Hill function.

\section{Discussion}

The results of this study show the cardiac action of dexchorpheniramine. This drug prolonged the QRS at higher concentrations. Many drugs that block the cardiac $\mathrm{Na}+$ channel are associated with QRS prolongation. ${ }^{18-20}$ Pharmacological inhibition of the cardiac $\mathrm{Na}+$ channel can be associated with intracardiac conduction delay, and may also trigger arrhythmias and can be associated with an increased mortality rate. ${ }^{18-20} \mathrm{H} 1 \mathrm{~A}$ as diphenhydramine, ${ }^{21}$ and brompheniramine $\mathrm{e}^{22}$ inhibited the $\mathrm{Na}+$ current. It cannot discard with these results that the mechanism for which dexchorpheniramine prolongued QRS interval was the $\mathrm{Na}+$ current blockade.

In the present results dexchorpheniramine significantly slowed the QT interval at the most higher concentrations. However, dexchorpheniramine did not significantly alter the QTc interval. Similar results were obtained by Salata et al. ${ }^{11}$ in chloraloseanesthetized dogs, (+)-chlorpheniramine did not significantly alter the QTc interval at doses up to $3.0 \mathrm{mg} / \mathrm{kg} \mathrm{IV.} .^{11}$ Some H1A (clemastine, hydroxyzine, brompheniramine, chlorpheniramine, diphenhydramine, cyproheptadine, chlorcyclizine, and promethazine) lengthened the QT interval of electrocardiogram of isolated perfused feline hearts. ${ }^{8}$ In this case the concentration of chlorpheniramine for the significative lengthening of QT was $10 \mu \mathrm{mol} / \mathrm{L}$, less than the concentration in the present results as of $30 \mu \mathrm{mol} / \mathrm{L}$. For the other alkylamine, brompheniramine lengthened the QT interval since $1 \mu \mathrm{mol} / \mathrm{L} .{ }^{8}$ Katchman et al. ${ }^{9}$ considered to chlorpheniramine as low-potency hERG current blocker (IC50 $=13 \mu \mathrm{mol} / \mathrm{L}$ ). ${ }^{9}$ Similar results obtained Hong et al. ${ }^{10}$ where chlorpheniramine also inhibits hERG channels expressed heterologously in Xenopus oocytes with an IC50 value of $\sim 20 \mu \mathrm{mol} / \mathrm{L}^{10}$

Drugs prolong the QT interval by blocking voltage-gated K+ channels, especially the rapid component of the delayed rectifier potassium current IKr, expressed by hERG.$^{23}$ Rat hearts are believed to be less susceptible to these effects because of their dominant transient outward $\mathrm{K}+$ current (Ito), which is believed to override any effect on $\mathrm{IKr}^{24}$ However, some studies have shown that cardiotoxic drugs prolong QT interval in rodents, and electrocardiogram recording in rats has been used as a screening tool in cardiotoxicity studies. ${ }^{25}$

It needs to be noted that the translation of the results of those studies to humans has limitations. This is because rats' hearts do not express the hERG. However, the rats' hearts express a variant of Ether-a-gogo-Related Gene (rat ERG, also known as Kenh2), ${ }^{26}$ which may play 
a role in drug induced cardiotoxicity, but further research is needed to support this notion.

In the last years, it has increased the attention on other channels that also can affect this parameter (QT interval), as $\mathrm{Na}+$ channel. $^{27}$ Already commented previously the report of some H1A with $\mathrm{Na}+$ channles. Moreover, the therapeutic plasma concentrations of (+)-chlorpheniramine are between 12.5 and $30 \mathrm{nmol} / \mathrm{L},{ }^{28}$ lower than the concentration required to produce significant contractile and electrical effects in the present results. With these limitations, it has nevertheless shown that conventional H1A can cause concentrationdependent cardiac contractile and electrical effects.

All hearts in this study experimented arrhythmias as bradycardia and ventricular premature beats since $10 \mu \mathrm{mol} / \mathrm{L}$ of dexchlorpheniramine. Others H1A like chlorpheniramine and diphenhydramine block cardiac $\mathrm{K}+$ and $\mathrm{Na}+$ channles in this range of concentrations and produce arrhythmias that can become severe..$^{5,29-30}$

Multicentric studies report that some H1A shown risk to cause arrhythmias including dexchorpheniramine. ${ }^{31,32}$ According to the present results, dexchorpheniramine decreased the cardiac force of contraction in concentration dependent manner, reaching a maximum of inhibition of $75.6 \pm 19.87 \%$ to the highest studied concentration $(300 \mu \mathrm{mol} / \mathrm{L})$. Not it knows about the effects of H1A on cardiac contraction, but due to that parameter depends principally of calcium influx, some authors have shown that some H1A block cardiac calcium current. So, brompheniramine, an H1A structurally related with dexchorpheniramine, blocked the cardiac calcium current. ${ }^{22}$ With the present results it cannot affirm the effect of dexchlorpheniramine on calcium current. Future studies are needed to clarify these findings.

\section{Conclusion}

In this work dexchlorpheniramine shows direct contractile and electric cardiac effects in concentration dependent manner. However, these actions were observed to higher concentrations than the plasmatic concentrations of therapeutic doses. These results suggest that dexchlorpheniramine exerted a multi-ion channel-blocking action in the heart, and it that requires further studies. These conclusions may account for clinical data that have been reported previously.

\section{Acknowledgements}

This work was supported by the Cuban Ministry of Public Health (Project No. 1502301).

\section{Conflict of interest}

The authors declare no conflict of interest.

\section{References}

1. Hass HL, Sergeeva OA, Selbach O. Histamine in the nervous system Physiol Rev. 2008;88(3):1183-1241.

2. Woosley RL. Cardiac Actions of Antihistamines. Annu Rev Pharmacol Toxicol. 1996;36:233-252.

3. Taglialatela M, Castaldo P, Pannaccione A, et al. Cardiac ion channels and antihistamines: possible mechanisms of cardiotoxicity. Clin Exp Allergy. 1999;29(3):182-189.

4. Taglialatela M, Timmerman H, Annunziato L. Cardiotoxic potential and CNS effects of first-generation antihistamines. Trends Pharmacol Sci. 2000;21:52-56.
5. Simons FER, Simons KJ. Histamine and H1-antihistamines: celebrating a century of progress. J Allergy Clin Immunol. 2011;128(6):1139-1150.

6. Martínez LG, González GEC. Cardiotoxicity of H1-antihistamines. $J$ Anal Pharm Res. 2018;7(2):197-201.

7. Vickers M. Dextro-chlorpheniramine (polaramine) in allergy: preliminary report of 75 patients and comparison with racemic chlorpheniramine (chlor-trimeton) in 39 patients. J Maine Med Assoc. 1959;50(1):16-20.

8. Wang WX, Ebert SN, Liu XK, et al. "Conventional” antihistamines slow cardiac repolarization in isolated perfused (Langendorff) feline hearts. $J$ Cardiovasc Pharmacol. 1998;32(1):123-128.

9. Katchman AN, Koerner J, Tosaka T, et al. Comparative evaluation of HERG currents and QT intervals following challenge with suspected torsadogenic and nontorsadogenic drugs. J Pharmacol Exp Ther. 2006;316(3):1098-1106.

10. Hong HK, Jo SH. Block of HERG k channel by classic histamine h (1) receptor antagonist chlorpheniramine. Korean J Physiol Pharmacol. 2009;13(3):215-220

11. Salata JJ, Jurkiewicz NK, Wallace AA, et al. Cardiac electrophysiological actions of the histamine H1-receptor antagonists astemizole and terfenadine compared with chlorpheniramine and pyrilamine. Circ Res. 1995;76(1):110-119.

12. Chouinard G, Ghadirian AM, Jones BD. Death attributed to ventricular arrhythmia induced by thioridazine in combination with a single Contac C capsule. Can Med Assoc J. 1978;119:729-731.

13. Nia AM, Fuhr U, Gassanov N, et al. Torsades de pointes tachycardia induced by common cold compound medication containing clorpheniramine. Eur J Clin Pharmacol. 2010,66(11):1173-1175.

14. Venkatraman N, O'Neil D, Hall AP. Life-threatening overdose with lamotrigine, citalopram, and chlorpheniramine. J Postgrad Med. 2008;54(4):316-317

15. Ösken A, Yegleç NS, Zehir R, et al. Torsades de pointes induced by concominant use of chlorpheniramine and propranolol: An unusual presentation with QT no prolongation. Ind J Pharmacol. 2016;48(4):462465 .

16. Galán L, Talavera K, Vassort G, et al. Characteristics of $\mathrm{Ca} 2+$ channel blockade by oxodipine and elgodipine in rat cardiomyocytes. Eur $J$ Pharmacol. 1998;357(1):93-105.

17. Curtis MJ, Hancox JC, Farkas A, et al. The Lambeth Conventions (II): Guidelines for the study of animal and human ventricular and supraventricular arrhythmias. Pharmacol Ther. 2013;139(2):213-248.

18. Madias JE. Drug-induced QRS morphology and duration changes. Cardiol J. 2008;15(6):505-509.

19. Harmer AR, Valentin JP, Pollard CE. On the relationship between block of the cardiac $\mathrm{Na}+$ channel and drug-induced prolongation of the QRS complex. Br J Pharmacol. 2011;164(2):260-273.

20. Lu HR, Hermans AN, Gallacher DJ. Does terfenadine-induced ventricular tachycardia/fibrillation directly relate to its QT prolongation and Torsades de Pointes? Br J Pharmacol. 2012;166(4):1490-1502.

21. Kuo CC, Huang RC, Lou BS. Inhibition of $\mathrm{Na}(+)$ current by diphenhydramine and other diphenyl compounds: molecular determinants of selective binding to the inactivated channels. Mol Pharmacol. 2000;57(1):135-143.

22. Shin WH, Kim KS, Kim EJ. Electrophysiological effects of brompheniramine on cardiac ion channels and action potential. Pharmacol Res. 2006;54(6):414-420.

23. Roden DM. Predicting drug-induced QT prolongation and torsades de pointes. J Physiol. 2016;594(9):2459-2468. 
24. Gralinski MR. The dog's role in preclinical assessment of QT interval prolongation. Toxicol Pathol. 2003;31:11-16.

25. Konopelski P, Ufnal M. Electrocardiography in Rats: a Comparison to Human. Physiol Res. 2016;65(5):717-725.

26. Matus M, Kucerova D, Kruzliak P, et al. Upregulation of SERCA2a following short-term ACE inhibition (by enalaprilat) alters contractile performance and arrhythmogenicity of healthy myocardium in rat. $\mathrm{Mol}$ Cell Biochem. 2015;403(1-2):199-208.

27. Chen MX, Helliwell RM, Clare JJ. In vitro profiling against ion channels beyond hERG as an early indicator of cardiac risk. Curr Opin Mol Ther. 2009;11(3):269-281.

28. Tagawa M, Kano M, Okamura N, et al. Differential cognitive effects of ebastine and (+)-chlorpheniramine in healthy subjects: correlation between cognitive impairment and plasma drug concentration. Br J Clin Pharmacol. 2002;53(3):296-304.
29. Joshi AK, Sljapic T, Borghei H, et al. Case of polymorphic ventricular tachycardia in diphenhydramine poisoning. J Cardiovasc Electrophysiol. 2004;15(5):591-593.

30. Thakur AC, Aslam AK, Aslam AF, et al. QT interval prolongation in diphenhydramine toxicity. Int J Cardiol. 2005;98(2):341-343.

31. Poluzzi E, Raschi E, Godman B, et al. Pro-Arrhythmic Potential of Oral Antihistamines (H1): Combining Adverse Reports with Drug Utilization Data across Europe. PLoS ONE. 2015;10(3):e0119551.

32. Poluzzi E, Diemberger I, De Ridder M, et al. Use of antihistamines and risk of ventricular tachyarrhythmia: a nested case-control study in five European countries from the ARITMO project. Eur J Clin Pharmacol. 2017;73(11):1499-1510. 